\title{
Democratic Legitimacy and the Paradox of Persisting Opposition
}

\author{
Iñigo González-Ricoy
}

Published at the Journal of Applied Philosophy, Vol. 34, No. 1, February 2017

doi: $10.1111 /$ japp. 12136

The paradox of persisting opposition raises a puzzle for normative accounts of democratic legitimacy. It involves an outvoted democrat who opposes a given policy (because she considers it to be unjust) while supporting it (because it is the upshot of majority rule). The paper makes a threefold contribution to the existing literature. It firstly considers pure proceduralist and pure instrumentalist alternatives to solve the paradox and finds them wanting-on normative, conceptual, and empirical grounds. Second, it presents a solution based on a two-level distinction between substantive and procedural legitimacy that shows that citizens are consistent in endorsing the upshot of democratic procedures while opposing it. Third, it unpacks three moral reasons to non-instrumentally endorse such proceduresnamely, the presence of reasonable disagreement, non-paternalism, and the right to do wrong. In so doing, the twolevel solution goes beyond those accounts of democratic legitimacy that rely on reasonable disagreement as a necessary condition for the paradox being solved.

Keywords: Wollheim's paradox, democracy, legitimacy, the value of political liberties

\section{Introduction}

An old concern in democratic theory is the puzzle of persisting opposition, as Robert Goodin has labeled it - the fact that in democratic polities citizens observe laws that they nonetheless regard as unjust. ${ }^{\mathrm{i}}$

The fact is not only philosophically puzzling. Given its centrality in democratic politics, it is also disturbing. In parliamentary systems with plurality voting, for instance, the party with an absolute parliamentary majority is often the preferred option of only a simple majority of the electorate. And in proportional systems, in which coalitions are the norm, political parties often 
compromise the policies for which they were voted in order to form a government coalition. In both cases, the preferred policies of part of the electorate are outvoted.

Sometimes, outvoted citizens update their beliefs to those of the winning majority. Some other times, by contrast, they opt for civil disobedience to express their disagreement, with serious consequences for the stability of the polity. In well-functioning democracies, however, these phenomena are marginal. More often than not, outvoted citizens whole-heartedly, i.e. not instrumentally, observe the enacted policies - even if puzzlingly, for they still consider them unjust. In this paper I contend that this puzzle is merely apparent, and advance three reasons why citizens are both consistent and morally justified in whole-heartedly endorsing the enacted policies while they oppose them.

The alleged puzzle is formalized in political philosophy as Wollheim's paradox. ${ }^{\text {ii }}$ The paradox involves a citizen $\mathrm{X}$ who believes that

(A1) Policy $A$ ought to be enacted.

However, since $\mathrm{X}$ is a democrat, she also believes that

(A2) The policy chosen by the majority ought to be enacted.

Now, assume that it is the case that

(A3) The policy chosen by the majority is policy $B$ (which is incompatible with $A$ ).

Therefore, from (A2) and (A3) it follows that $\mathrm{X}$ also believes - at first sight inconsistently with 
(A1)-that

Policy $B$ ought to be enacted.

The paradox has been widely employed in the recent literature. Yet it has been much less analyzed. With some notable exceptions, ${ }^{\text {iii }}$ recent democratic theory has taken its solution as given, and has applied it to recent debates on the authority of law, Bayesian updating, deliberative democracy, or political compromise. ${ }^{\text {iv }}$

Unlike these contributions, the present paper goes back to the paradox, and shows why there is nothing paradoxical in it. It firstly discusses the existing solutions, which are divided into three general types. The first two types acknowledge the paradox, and attempt to subsume either (A1) to (A4) or (A4) to (A1), ${ }^{\mathrm{v}}$ while a third type attempts to show that (A1) and (A4) need not be at odds. ${ }^{\text {vi }}$ The paper assesses the two first types as instances of pure proceduralist and pure instrumentalist accounts of democratic legitimacy, respectively, and finds them wanting. It then provides a solution of the third sort-call it the two-level solution - that shows that citizens are consistent in simultaneously endorsing (A1) and (A4) because these endorsements derive, respectively, from principles of substantive and procedural legitimacy that are compatible with each other. Once this has been done, the paper advances three independently sufficient moral reasons for X to non-instrumentally endorse (A2), and therefore (A4), while still backing up (A1) - namely, the presence of reasonable disagreement, non-paternalism, and the right to do wrong. In advancing these reasons, the two-level solution goes beyond such accounts, predominant in the recent literature, that rely on the presence of reasonable disagreement as a necessary condition for X's endorsement of (A2) to be justified, thus avoiding some of their shortcomings. 
The solution operates under three assumptions that should be set out from the outset. The first is that X's endorsement of (A1) and of (A2) is morally motivated and reasonable. The solution may also apply if this assumption is relaxed, but I do not explore this possibility here. ${ }^{\text {vii }}$ The second assumption is that the scope of (A2) is limited to internal political affairs, i.e. to political decisions that only affect the members of the political community. Political decisions involving externalities (e.g. war declaration, fisheries policy, greenhouse emission control) are therefore not considered here. The third assumption is that well-functioning democratic procedures are in place. This means that each citizen's political input is treated equally and that adequate channels to express dissent (e.g. the right to associate, to demonstrate, to submit initiatives to parliament) are available. When these assumptions do not obtain, the reasons to embrace (A2) may have less force, or not apply at all, and the conclusions of this paper may not follow as a result. viii

The task of the paper is threefold - conceptual, normative, and explanatory. It is mainly aimed at showing why citizens are consistent and morally justified in sticking to democratic procedures when such procedures bring about outcomes that they consider unjust. In so doing, however, it also attempts to make sense of actual citizens' endorsement of such procedures, thus shedding light on the alleged puzzle of democratic stability under conditions of persisting opposition.

The paper proceeds in six further sections. Sections 2 and 3 address the two aforementioned ways out of the paradox. Section 4 unpacks the two-level solution. Sections 5 and 6 advance three independently sufficient moral reasons to ground the solution. A conclusion closes the paper.

\section{The Rousseauian solution}

Let us begin with a first possible way out of the paradox-call it the Rousseauian solution. It 
includes two claims. First, there is a contradiction in X endorsing both (A1) and (A4). Second, when this is the case, $\mathrm{X}$ can nevertheless update her beliefs. Once she realizes that $B$ is the majority policy, she can turn to believe that $B$ rather than $A$ ought to be enacted.

When this is the case, it turns out that $\mathrm{X}$ is not truly committed to (A1). For when she firstly expressed her preference for $A$, such preference was conditional on other people's beliefs. In short, she rather believed that

(A1*) $\quad A$ ought to be enacted provided that a majority is of the same opinion.

Adapting Rawls's taxonomy of proceduralism, we can refer to $\mathrm{X}$ under the Rousseauian solution as "pure proceduralist." For she endorses the democratic process regardless of the content of its substantive upshot, as if no process-independent criterion to evaluate such upshot existed. $^{\text {ix }}$ Three difficulties arise with this solution, though-conceptual, empirical, and normative ones.

Let us begin with the conceptual difficulty. Assume that voters systematically address Wollheim's paradox by updating their beliefs to those of the majority. In politics, this is often the case due to strategic voting, bandwagon effects, or the preference-shaping effects of law, but also because of perfectly rational changes of mind under conditions of imperfect information on political issues that are often complex to tackle. ${ }^{\mathrm{X}}$ When that is the case, $\mathrm{X}$ may update her preferred policy to what she perceives as the majority will. If $B$ is eventually chosen by the majority, $\mathrm{X}$ will then admit, given that she is committed to (A2), that she was wrong in her calculus, and will turn to believe that $B$ rather than $A$ ought be enacted. If, on the contrary, $A$ is eventually chosen, $\mathrm{X}$ will continue to believe that $A$ rather than $B$ ought to be enacted. Yet only because a majority has chosen $A$ over $B$, rather than because she believes that $A$ ought to be 
enacted.

There is nothing individually inconsistent or irrational in how pure proceduralists behave. The problem arises when we generalize their voting pattern and apply it to all voters. In order to see why, assume that

Every voter believes that $A$ ought to be enacted provided that a majority is of the same opinion.

For simplicity, let us put aside marginal cases in which voters may vote for alternatives that they do not believe should be enacted. ${ }^{\mathrm{xi}}$ If we only consider those who vote for the alternative that they wish to have enacted, then it follows that

Every voter will cast their vote according to what they anticipate that a majority will vote for, rather than according to what they really believe.

But then it also follows that

$$
\begin{aligned}
& \text { Since every vote is a function of everyone else's votes, the policy that the majority } \\
& \text { votes for turns out to be indeterminate. }
\end{aligned}
$$

As an analogy, consider the case of someone - call her Mary — who distrusts her own ability to wisely order in a restaurant. When having to order a dish to share with friends, Mary usually votes for whatever the majority orders. Or, in order to keep the analogy accurate, she votes for whatever she believes that the majority will order. There is nothing irrational or inconsistent in 
doing this. However, her conduct makes sense only insofar as (at least some of) her friends trust their own criteria. If all of them were as hesitant as Mary, then none of them would be able to delegate their decision. Being the majority decision a function of individual decisions that are, in turn, a function of the majority decision, the majority decision would become indeterminate. ${ }^{\text {ii }}$

The second problem is explanatory. Admittedly, the conceptual problem does not challenge the solution insofar as enough citizens refrain from delegating their decision. And this seems to be the norm in democratic societies. But, in that case, it turns out that the solution does not make sense precisely of voters that are not pure proceduralists, i.e. of those voters who whole-heartedly believe that $A$ rather than $B$ ought to be enacted. This is often the case both before and after going to the polls. And there is nothing irrational about it. In democratic politics, it is not infrequent to vote for $A$ knowing how the voting will go and, often, knowing quite well that you will be outvoted. xiii $^{\text {. }}$

Further, many voters oppose the majority policy once it has been enacted-often speaking out against it in demonstrations or petitioning - without calling into question its legitimacy, i.e. while whole-heartedly observing it. As Waldron has pointed out, an adequate account of the law's authority must accommodate the fact that the law "makes its demand ex hypothesi on someone who thinks he has good ground for believing that the legislature is mistaken."xiv

The third problem is normative. Unlike the previous problem, it concerns pure proceduralist voters, i.e. those voters who update their policy preferences to those of the majority. The problem is that it is unclear why their votes should have as much normative weight as the votes of those who vote for what they whole-heartedly believe. ${ }^{\mathrm{xv}}$ After all, democracy is a procedure employed to reflect citizens' preferences about policies that pervasively affect their lives, that are coercively enforced against them, and that are funded through their taxes. Democratic procedures are morally appealing, and their directives are authoritative, because among other things they 
channel citizens' preferences about the policies that they take to be correct, and about issues on which their stakes are high. ${ }^{\text {xvi }}$ Going back to the above analogy, should Mary's vote and the votes casted by her less hesitant friends have the same weight? I take it that the correct answer is that they should not.

It might be objected that this goes against the common democratic principle of giving equal weight to all votes irrespective of their origin or supposed quality. ${ }^{\text {xvi }}$ I raise three points in response. First, the fact that some votes are of less quality than others does not imply that those who cast the former should not have the legal right to vote, not only for pragmatic reasons, but also because voters might have a legal right to do wrong. ${ }^{\text {xiii }}$ Second, it is not uncommon to assume that not all votes are of equal value (being epistemic failures the clearest example of bad voting, and the reason why certain epistemic preconditions, such as literacy, are generally required for the adequate functioning of democracy). ${ }^{\mathrm{xix}}$ There is ground, thus, to claim that pure proceduralist votes may be less valuable. Third, that these votes do have less moral weight is shown by the generalization made in the presentation of first concern above. To see why, assume that every single citizen voted the predicted majority decision, and that no one at all voted the option she takes to be correct. If that were the case, I take it that the justification of democracy would be under serious threat.

In short, the three concerns raised here pose a dilemma to the Rousseauian solution. The more citizens behave as pure proceduralists, thus updating their beliefs to those of the majority, the more indeterminate the upshot of the democratic procedure is, and the less morally valuable it is. And, conversely, the less citizens behave as pure proceduralists, the more determinate and morally valuable the decision is, yet the less relevant the Rousseauian solution turns out to be in making sense of how citizens behave under conditions of persisting opposition. 


\section{The Hobbesian solution}

Consider now another possible way out of the paradox-call it the Hobbesian solutionaccording to which X's endorsement of (A2) is conditional on majority rule bringing about the just outcome, i.e. policy $A$. Accordingly, when policy $B$ rather than policy $A$ results from majority rule, X's endorsement of (A2) is merely prudential, i.e. she observes policy $B$ not because she takes it to be legitimate, but rather because she would be worse-off otherwise. State coercion and social pressure are two obvious reasons for compliance under these circumstances. But additional and perhaps more subtle reasons may also apply, such as rule-consequentialist ones. For example, $\mathrm{X}$ can simultaneously believe that $A$ ought to be enacted and that $B$ ought to be observed because law-keeping has desirable consequences. ${ }^{\mathrm{xx}}$

Under either reading, however, the democratic procedure included in (A2) only has instrumental value, and $\mathrm{X}$ only has instrumental reasons to endorse it. ${ }^{\text {xi }}$ Hence, when the procedure brings about an outcome that is at odds with what $\mathrm{X}$ takes to be just, as in the case of Wollheim's paradox, then X does not have any reason, other than prudential ones, to stick to the procedure.

Again, explanatory, normative, and conceptual problems arise with this solution. Consider the explanatory problem first. The Hobbesian solution implies that the only reason why pure instrumentalists do not enact $A$ is that they lack the social and political resources required to do so, or that they so perceive to be the case. If $\mathrm{X}$ happened to enjoy such resources, they would enact $A$ without batting an eyelash. Barry expressed this view with his usual clarity:

If you adhere to any ideal or principle which does not include in it a reference to the opinion of others, then it is logically possible that you might be the only person holding it. There could be a situation, therefore, in which you say 'So and so should be done' and everyone except you 
says 'So and so should not be done.' You are in effect setting yourself up as a dictator. Of course, you probably won't have the power to get what you want done against everyone's opposition, nevertheless you are saying that if you had the power you would. ${ }^{\text {xii }}$

However, when it comes to actual citizens, it is both plausible and empirically sound to think that they can, and indeed do, behave otherwise. It is certainly plausible to think that citizens may favor policy $A$, have the (actual and perceived) power to enact $A$, and yet hesitate to do so because they also believe that $A$ ought not to be enacted by any possible means, but only by democratic ones. ${ }^{x x i i i}$ This may be for the reasons that are listed in the next objection below and unpacked in sections 5 and 6 , or for some further reasons. Further, empirical evidence shows that, in deciding whether to comply with governmental policies, citizens do attach great value to the fairness of the procedures employed to produce them. Indeed, this dimension often exceeds their outcome evaluations. ${ }^{x x i v}$ In a review of the relevant literature, Tom Tyler concludes the following: "studies of the legitimacy of authority suggest that people decide how legitimate authorities are, and how much to defer to those authorities and to their decisions, primarily by assessing the fairness of their decision-making procedures." ${ }^{\text {xxv }}$

The second objection is normative. Many Hobbesians admit that actual citizens attach intrinsic value to democratic procedures. ${ }^{x x v i}$ However, they do not bother. They contend that this psychological fact should have no bearing in normative theorizing, which should only consider whether there are moral reasons to attach non-instrumental value to such procedures. However, even if we assume this clear-cut separation between the descriptive and the normative, a problem for the Hobbesian solution is that such moral reasons are available. ${ }^{\text {xxvi }}$

In sections 5 and 6 , I unpack three reasons for citizens to stick to the upshot of democratic procedures provided that such procedures are fair and regardless of whether they bring about the 
outcomes that they take to be just or not. For now, let me just enumerate them. First, democratic procedures have non-instrumental value in the presence of thick reasonable disagreements about which outcomes are just. Second, they have non-instrumental value because they are necessary to avoid paternalizing citizens. Third, they have non-instrumental value because they respect citizens' democratic right to do wrong. If these reasons - or some further ones, such as ensuring citizens' equal social status and their sense of self-respect-were sound, then it would turn out that democratic procedures are not only instrumentally valuable. Of course, they would not imply that they do not have instrumental value at all. They could have both, as we shall see below.

Consider finally the conceptual problem. Assume that the Hobbesian solution is sound. Citizens should, and would, enact $A$ if they happened to have the (actual or perceived) power to do so. This is the position endorsed by Arneson, who claims the following: "If you happen to have the power to implement [the] correct assessment, you should do so, despite the fact that your assessment will not attract the unanimous assent of those affected."xxviii

The problem with this solution is twofold. First, it is questionable whether pure instrumentalists, who are willing to enact their preferred policies regardless of their fellow citizens' consent, can qualify as democrats at all. After all, being a democrat implies, almost as a matter of definition, being morally committed (at least to some degree) to the decisions brought about by democratic means. This, however, is not a problem for most Hobbesians, who openly assume that they are democrats only contingently. ${ }^{\text {xxix }}$ Second, letting aside the definitional issue, the Hobbesian solution does not solve the paradox. It only evades it. For the paradox consists in believing that two inconsistent pieces of legislation ought to be enacted. Accordingly, Hobbesian attempts to address the paradox, such as Weiss's, do not have a bearing on Wollheim's paradox. This is supposed to involve a democrat in saying at the same time that $A$ ought to be enacted and $B$ ought to be enacted, being $A$ and $B$ incompatible with each other. ${ }^{\mathrm{xxx}}$ 


\section{The two-level solution}

The Rousseauian and the Hobbesian accounts attempt to solve Wollheim's paradox by trying to subsume (A1) to (A4) and (A4) to (A1), respectively. To be sure, citizens often have sound reasons to stick to democratic procedures, and to observe their upshot, as a means to update their own beliefs about which policies are just, as Rousseauians claim, and due to the ability of such procedures to bring about outcomes that are just, as Hobbesians do. Yet, as the previous two sections have shown, these solutions are not fully adequate. In the remainder of the paper, I will provide an alternative account that shows that the paradox is only apparent.

The two-level solution, as I shall refer to it, shows that citizens are consistent and morally justified in whole-heartedly observing the upshot of democratic procedures while opposing the policies resulting from them, i.e. without changing their minds about the policies that they reasonably take to be just. This solution draws upon contributions made by Harrison, Haksar, Waldron, and Wollheim, yet it crucially departs from them. It firstly shows that (A1) and (A4) can be consistently held when they are derived from a first-order principle of substantive legitimacy and a second-order principle of procedural legitimacy that address the questions, respectively, of "what ought to be done" and of "what ought to be done provided that we follow

the commands of a common legitimate authority."xxxi Next, it provides three independently sufficient moral reasons for $\mathrm{X}$ to endorse (A2) — and therefore (A4) — as strongly as she endorses (A1). In so doing, the solution goes beyond those accounts - dominant in the recent literaturethat rely on the existence of reasonable disagreement as a necessary rationale for the former endorsement.

I begin by showing why X's endorsement of (A1) and of (A4) derives from her endorsement of principles pertaining to two different normative levels. Assume, for refutation, that the paradox 
were just a particular case of the potential contradiction that can arise from general moral principles pertaining to the same level, rather than a paradox of democracy, as Harrison has claimed. $^{\text {xxxii }}$ Then, (A1) and (A2) would be incompatible under the circumstances specified by Wollheim. Yet, according to Harrison, only as principles like keeping promises and saving life can turn out to be incompatible under analogous circumstances (e.g. when I promised a friend that I would pick him up and, on the way to the airport, I find someone whose life is endangered and needs my help). According to Harrison, this would prove that there is no paradox as such:

In both cases two moral principles, not in themselves incompatible, become so in particular circumstances. If this were sufficient to create a paradox in democracy, it would be sufficient to create a paradox in promising. However, since it does not create a paradox in promising, it should not be taken to create one in democracy either. ${ }^{\text {xxiii }}$

Yet, this interpretation is incorrect. Wollheim's paradox is certainly a particular case of a more broad conflict between general principles. However, this interpretation falls short of capturing the difference between the principles in conflict in the above case (i.e. keeping promises and saving life) and the principles in Wollheim's paradox. In the above case both endorsements are to substantive moral principles. ${ }^{\text {xxiv }}$ In Wollheim's paradox, by contrast, the belief that “ $A$ ought to be enacted" surely obtains from X's endorsement of a substantive principle of legitimacy. It obtains from a general endorsement of what she regards as the correct policy, which is unconditional on third parties' views. However, the belief that " $B$ ought to be enacted" obtains from X's general endorsement of what she regards as the legitimate source of authority, i.e. from her endorsement of a principle of procedural legitimacy. ${ }^{\mathrm{xxx}}$

In the version of the paradox presented by Wollheim, the procedural principle to which $\mathrm{X}$ is 
committed takes the form of a democratic principle, according to which the policy chosen by the majority ought to be enacted, i.e. (A2). However, the source of authority that $\mathrm{X}$ regards as legitimate need not be democratic. Even though the moral reasons advanced below in sections 5 through 7 would certainly not justify some of the following, $\mathrm{X}$ could take as legitimate a number of diverse and not necessarily democratic procedural sources that could also trigger the paradox, including the following ones:

(A2) The policy chosen by the majority ought to be enacted.

(A2*) The policy chosen by the Pope ought to be enacted.

(A2**) The policy chosen by experts ought to be enacted.

$\left(\mathrm{A} 2^{* * *}\right) \quad$ The policy chosen by lottery ought to be enacted.

In order to clearly distinguish these two levels of substantive and procedural legitimacy, consider the questions to which Harrison's and Wollheim's commitments provide an answer. In Harrison's case, both commitments (keep promises and save life) provide an answer to the question of what ought to be done. In Wollheim's case, by contrast, “ $A$ ought to be enacted" provides an answer to the question of what ought to be done, while " $B$ ought to be enacted," unlike in the Hobbesian solution, provides an answer to the question of what ought to be done provided that we follow the commands of a common legitimate authority (and regardless of the content of its directives). ${ }^{\text {xxvi }}$

So displayed, the two-level solution dissolves the paradox. It displays $\mathrm{X}$ as observing policy $B$ due to her endorsement of the democratic procedure included in (A2), and endorsing its upshot as a result. And it shows that $\mathrm{X}$ can equally endorse $A$ as the policy she takes as substantively legitimate. Accordingly, in a well-functioning democracy, in which adequate channels to express dissent are available, $\mathrm{X}$ can speak out against policy $B$, which she substantively opposes in favor 
of $A$, by attending demonstrations, petitioning, or submitting initiatives to parliament, while she respectfully observes $B .^{\text {xxxvii }}$

Of course, the fact that it is consistent for $\mathrm{X}$ to endorse (A4) while upholding her endorsement of (A1) does not imply that she is morally justified in so doing. This will be addressed in the next section. In this section I only show that, under the two-level solution, the two commitments need not be inconsistent.

To illustrate this, let us consider an example taken from the military coup that deposed the Egyptian President Mohamed Morsi in July 2013, and let us focus on those who opposed the coup. Among these, at least two sorts of reactions are plausible. Some may have stood up against the putsch as a result of their substantive agreement with the policies enacted by Morsi and his government. Yet some others may have opposed the coup as a result of their endorsement of the democratic procedure used to appoint Morsi and, importantly for present purposes, despite the fact that they might have nevertheless opposed his policies. ${ }^{\text {xxxviii }}$

While those in the latter group have some obvious differences with the citizen depicted in Wollheim's paradox, they nicely illustrate the point raised here. They may have substantively opposed Morsi due to fact that they disagreed with his policies. However, at the very same time, they may also have supported him against the military coup due to their commitment to the democratic means used to elect him. In short, they could not be pure instrumentalists, for they may have opposed the coup for procedural reasons. Yet, they could not be pure proceduralists either, for at the same time they may have opposed the policies enacted by Morsi during his term in office.

This plausible reaction to the coup shows that there is nothing paradoxical in Wollheim's purported paradox when we see it from the standpoint of the two-level solution. Further, this reaction might have been marginal in the aftermath of the Egyptian putsch. However, it need not 
be uncommon in well-established democracies, in which adequate channels to express dissent (e.g. the right to associate, to demonstrate, to submit initiatives to parliament) are available and the willingness to submit to the directives of the democratic authority is widespread among citizens. In such democracies, Wollheim's paradox dissolves.

\section{The argument from reasonable disagreement}

The previous section has shown why, under the two-level solution, it is not inconsistent for $\mathrm{X}$ to endorse (A2) while backing up (A1). As noted above, however, this says nothing about whether such endorsements are morally justified or not. In this and the following two sections I focus on the former endorsement and advance three independently sufficient moral reasons that may justify it. Unlike the reasons advanced by the Hobbesian solution, these reasons are not instrumental. In addition, they are mutually non-exclusive (i.e. they can be combined), nonexhaustive (i.e. further reasons may be available), and pro tanto (i.e. further reasons may end up overriding them).

Among these, firstly consider the presence of reasonable disagreement, a reason that has dominated recent debates. ${ }^{\text {xxxix }}$ When this condition obtains, $\mathrm{X}$ can be committed to both (A1) and (A4) at the same time - to the former because it is the policy that she takes to be just and to the latter because she acknowledges that her fellow citizens have opposing, yet reasonable, views on (A1) and a common course of action is nevertheless to be taken. ${ }^{\mathrm{xl}}$ Under this interpretation, $\mathrm{X}$ is committed to (A1) as a matter of substantive legitimacy while endorsing (A2) as a matter of procedural legitimacy in the presence of reasonable disagreement on which substantive policies are just. As Waldron has put it,

A person who believes that $A$ is the right decision but $B$ the decision that should be 
implemented, is offering answers to two different, though complementary questions. That $B$ should be implemented is his answer to the question, 'What are we to do, given that we disagree about whether $A$ or $B$ is just?' That $A$ is the right decision is his own contribution to the disagreement that called forth that question. ${ }^{\text {li }}$

This is a very plausible interpretation of X's endorsement of both (A2) and (A1), one which given the rich literature examining it I will not discuss in detail. However, as we shall see in the following section, it is not the only plausible reason to justify X's endorsement of (A2).

Before turning to these reasons, consider two reasons why their availability is relevant for the issue at hand. A first reason is that they provide a more robust justification of democratic procedures than disagreement-based accounts. To see this, it should be recalled that the possibility of a consensus should not be ruled out. Disagreement is very context-sensitive. The same policies can trigger wide support in certain constituencies while giving raise to lively debate, to put it mildly, in some others. For example, linguistic policy is way more heated an issue in Belgium than in France; healthcare provision is way more heated an issue in the US than in Norway; and agrarian reform is way more heated an issue in Colombia than in Japan.

Disagreement-based accounts sometimes carefully take into account these variations. Yet they often reduce the non-instrumental value of decision-making procedures to a function of the existing degree of disagreement. Laura Valentini, for example, has recently argued that the intrinsic value of democratic procedures is conditional on the thickness of reasonable disagreement. ${ }^{\text {xlii }}$ The thicker the existing disagreement, the more intrinsically valuable democratic procedures are, and the thinner the existing disagreement, the less intrinsically valuable democratic procedures turn out to be. A relevant implication of this is that, if disagreement is absent, then non-instrumental reasons to endorse democratic procedures are also missing, and 
their justification is less robust. ${ }^{\text {xliii }}$ This, of course, is not obviously problematic. It may be the case that, in the absence of disagreement, democracy only has instrumental value. However, this is mistaken, for as we shall see there are non-instrumental reasons to endorse (A2) other than the presence of reasonable disagreement. A more robust justification of democratic procedures is thus possible.

The second reason why the existence of further reasons is important is that they provide a way out to the regress of procedures triggered by the presence of disagreement. It has often been argued that reasonable disagreement on substantive policies is also likely to pervade the

procedures used to address such disagreement. ${ }^{\text {xliv }}$ When that is the case, $\mathrm{X}$ is caught in a dilemma. She can, on the one hand, relax her commitment to (A2) due to the reasonable disagreement that pervades (A2). In so doing, however, she falls into the Hobbesian solution. On the other hand, she can endorse a further procedural principle in order to address the existing disagreement on (A2), such as the following one:

(A5) The procedure chosen by the majority ought to be enacted.

However, reasonable disagreement is likely to pervade (A5) as much as it pervades (A2) and (A1). Accordingly, this second strategy is likely to lead to a regress of procedures.

The dilemma poses a serious problem for disagreement-based solutions to the paradox. ${ }^{\text {xlv }}$ Yet it is more tractable under the two-level solution presented here, given that it is grounded on further independently sufficient reasons for $\mathrm{X}$ to endorse (A2). As such, the two-level solution is better equipped to justify such endorsement than disagreement-based accounts.

\section{Two further reasons: non-paternalism and the right to do wrong}


To justify the non-instrumental value of democratic procedures, reasons other than the presence of reasonable disagreement have been advanced. Two influential candidates are, first, securing citizens' equal social status and their sense of self-respect and, second, enabling citizens' participation in the process of social construction so that they all can feel at home in the social world. These are reasons that have already been considered in detail. ${ }^{\text {xlvi }}$ In this section I thus focus on two further reasons for $\mathrm{X}$ to non-instrumentally endorse (A2) - namely, that in so doing she avoids paternalizing her fellow citizens and respects their right to democratically do wrong.

Before analyzing these two reasons, a caveat is in order. The right not to be paternalized and the right to wrongdoing are very different. While the former refers to decisions that only affect the holder of the right, the latter refers to decisions that affect not only the holder but also third parties. Here, however, I treat them jointly. This is so for two reasons. The first is that both rights are equally grounded on the value of personal autonomy. The second and more important reason is that their scope need not be different once we make the following two methodological stipulations. The first is that the right not to be paternalized is only considered here collectively, i.e. as a right of a democratic polity not to be interfered by a third party—whether internal or external-with the policies concerning their internal affairs. The second stipulation is that, as noted at the outset of the paper, the scope of the right to do wrong is constrained to internal affairs, i.e. to political decisions by which citizens can democratically wrong some of the members of the community, and only them. Political decisions involving negative externalities (e.g. war declaration, fisheries policy, greenhouse emission control) are therefore not considered here. Thus constrained, the scope of the two rights coincides.

Let us now get started. Citizens often have morally dubious reasons to vote as they do. Yet, as Parfit has recently argued, even if they had no reasons at all, we would have one to respect their vote, namely to avoid imposing our will on them for their own good. ${ }^{\text {xlvii }}$ Consider tax reform. X 
may be certain of what a just distribution of fiscal burdens is, and may have the actual and perceived power to enact such reform. Still, she may defer to majority vote in order to avoid imposing what she takes to be just against the will of her fellow citizens, even if she may be convinced that they have no sound reason to vote against her preferred policy and that, in deferring to (A2), she will be outvoted.

What justifies the rights not to be paternalized and to do wrong is that they advance the value of personal autonomy. Individually, this right implies that individuals should have the ability to freely determine their lives and identity. ${ }^{\text {xviii }}$ Collectively, autonomy implies that individuals, as part of a democratic polity, should have the ability to democratically determine their collective identity. Citizens, and their elected representatives, often make political choices that are constitutive of such identity. Of course, only some of these choices (e.g. the ratification of the state constitution or the decision whether to join the NATO or the EU) are big enough to shape by themselves who they are as a polity. Yet the collective identity of citizens is also shaped, in the aggregate, by medium decisions, including decisions about criminal law, monetary policy, reproductive rights, territorial organization, hate speech, or welfare provision. ${ }^{\text {xlix }}$

This provides us with a twofold rationale for the rights not to be paternalized and to wrongdoing. The first is normative. As in the case of personal constitutive choices, such as who to marry or whether to have a child, political constitutive choices — and to a lesser extent, medium choices - are more valuable if they are freely made than if they are made out of coercion or by a third party. There is, thus, some value in letting citizens make their own political choices - and, accordingly, their own mistakes - that is based on the value of being able to shape one's own identity, i.e. on the value of self-constitution. ${ }^{1}$

The second rationale is logical. Imposing on citizens what is collectively best for them, when it comes to constitutive decisions, is not only paternalistic. It is also a nonstarter. This is not 
because of mere reactance, i.e. the adoption of a view or an attitude that is contrary to another view or attitude as a result exclusively of the latter being imposed on her. Rather, it is a nonstarter because what is best for someone with regard to constitutive decisions cannot be defined before the decision is made, on the one hand, and is to a great extent dependent, on the other hand, on who makes the decisions. When it comes to constitutive decisions, what is best cannot be neither defined nor fully achieved, if at all, by a third party, such as X.

Before turning to potential objections, two caveats are in order. The first is that the above reasons may be easily overridden or not apply whatsoever when the upshot of (A2) results from misinformed or not-fully voluntary choices. That is, other things being equal, enacting policy $A$ against the majority will out of soft paternalism may be justified. However, enacting policy $A$ is hardly justifiable when it implies hard paternalism, i.e. when (A4) results from fully informed and fully voluntary votes of a majority of citizens. ${ }^{\text {li }}$ Further, recall that, in addition, we are assuming that citizens vote from moral and reasonable convictions. This satisfies an important requirement of the right to do wrong, namely that the wrongs are made in good faith. As Waldron suggests, it cannot be the case that choice is so important that needs to be protected yet so unimportant that guidance is out of the question. ${ }^{\text {lii }}$

The second caveat is that the aforementioned reasons are not decisive in justifying X's endorsement of (A2), since democratic procedures can sometimes lead to collective mistakes that are morally too gross or that affect individuals that do not have an input in the decision (e.g. immigrants without the right to vote). Here I am only claiming that there is some value, for the citizens of a polity, in being able to make their own mistakes, which is very different from the (highly implausible) claim that there is nothing else valuable or that this ability overrides all other moral considerations. However, if we believe that it is morally valuable for citizens of a polity to have a right to make their own decisions and shape their own collective identity, then $\mathrm{X}$ has a pro 
tanto reason to endorse (A2), and therefore (A4), at least when her fellow citizens act in good faith. If she imposed her own criterion against their will to advance what she takes to be collectively good for them, $\mathrm{X}$ would violate their right to do wrong and, in so doing, she would paternalize them.

Consider now two potential concerns. Øverland and Barry, who oppose the democratic right to do wrong, advance the first concern. They admit that when citizens vote from sincere and reasonable convictions, the range of means that it would be permissible to use to prevent them from doing wrong are much more reduced than when they vote from self-interest. Yet, this is different from having a democratic right to do wrong, they contend. It puts constrains on the means that are permissible to prevent wrongdoing, but does not justify such a right. ${ }^{\text {lii }}$

Now, according to them, to adequately assess the means that are morally permissible, we must consider their costs. Sometimes, they contend, the costs of thwarting the wrong may exceed the benefits, in which case such means will not be permissible. But, if $\mathrm{X}$ is completely certain that policy $B$ should not be enacted because it is unjust, then I take it that this implies that the costs of $B$, including the costs of its being prevented, exceed its benefits. Yet, if so, which could be the further costs to which Øverland and Barry refer? Two apt candidates come to mind. The first is compliance costs arising from morally motivated disagreement with the enacted policies. (It should be noted that, in raising their concern, Øverland and Barry assume that citizens act exclusively from moral reasons, which rules out compliance costs arising from self-interested motivations.) The second candidate is the costs arising from trumping citizens' autonomy and their ability to make their own decisions if policy $A$ instead of policy $B$ is enacted. However, these are precisely the values that ground the democratic right to do wrong, as well as the right not to be paternalized. Since, as I have argued above, these two rights can be overridden when they lead to serious wrongdoing, it seems more consistent to say that citizens have a right to 
wrongdoing and a right not to be paternalized and that these rights are merely pro tanto - rather than saying, on the one hand, that they do not have such rights and, on the other, that the costs of thwarting their wrongdoing may often justify letting them do wrong.

A second worry is that the very idea of paternalizing someone may only hold in the presence of disagreement, i.e. when a majority of voters oppose the policy that $\mathrm{X}$ takes to be collectively good for them and $\mathrm{X}$ has to decide whether to observe their preferred policy it or not. If this were the case, it could be further objected that the argument from non-paternalism adds little to the argument from disagreement. I advance two responses in reply. The first is that the fact that this is an argument that only holds under certain conditions (i.e. when disagreement obtains) should not make us confuse it with the reason for it (which is different from the acknowledgment of reasonable disagreement). One thing is to submit to democratic procedures because you acknowledge that your fellow citizens have different, yet reasonable, views and that a common course of action is nevertheless to be taken. Quite another thing is to do it because you think that, when a majority of your citizens disagree with you, you should not impose your will if you could because, in so doing, you would be undermining their personal autonomy and their capacity of self-constitution. The second response is that it is indeed possible to paternalize someone when disagreement does not obtain. This goes against the common belief that you can paternalize someone only if you act against her will. ${ }^{\text {liv }}$ Yet, this is not necessarily true. In order to see why, consider the following case: $:^{1 \mathrm{v}}$

Julie. You and your group of friends hang out together every now and then. You are all open to a plurality of options except Julie, who detests hiking, as everybody knows well. When you arrange a weekend of hiking, you phone each of them to invite them. But you do not phone Julie, since you know that she dislikes hiking. However, when she learns that you have invited 
all others except her, she gets upset. She would have declined the offer had you invited her. Yet, she finds presumptuous that you did not ask her. She believes that by assuming her preferences instead of actually asking her you have paternalized her.

Julie is hardly the typical case of paternalism, which usually requires the paternalizer to act against the will of the paternalizee. Yet it allows us to see that neither the presence of disagreement nor acting against the will of the paternalizee are strictly necessary for paternalism. It is possible to paternalize someone when you do what she would have done nevertheless (as when, in Julie, you did not phone her because you were certain that she would have declined the offer, which she would indeed have done had you phoned her). What is relevant is whether potential paternalizer acts from what the potential paternalizee has chosen to do. ${ }^{\text {lvi }}$ Mutatis mutandis, it would be possible for X to paternalize her fellow citizens if the upshot of (A2) did not differ from her preferred policy $A$. X would do this if she enacted policy $A$ because $A$ is the policy that she takes to be collectively good for her fellow citizens rather than because $A$ is the policy chosen by (a majority of) them. In acting from the former reason, X paternalizes them.

\section{Conclusion}

The paper has firstly considered two alternative solutions to the paradox of persisting opposition and has found them wanting - on normative, conceptual, and empirical grounds. It has then advanced a two-level solution to the paradox. Finally, the paper has advanced three moral reasons for citizens' non-instrumental endorsement of democratic procedures-namely, the presence of reasonable disagreement, non-paternalism, and the right to do wrong.

The two-level solution operates under the three methodological assumptions that have been set out at the outset of the paper. In addition, the solution is grounded on reasons that are 
mutually non-exclusive (i.e. they can be combined), non-exhaustive (i.e. they can be complemented by further reasons), and pro tanto (i.e. they can be overridden by further reasons). Further research is thus required, first, to see how the solution is affected when we relax the aforementioned assumptions and, second, to establish how the reasons examined here relate to each other, which reasons can complement them, and under which conditions they may be overridden.

\footnotetext{
${ }^{i}$ Robert E. Goodin, 'The Paradox of Persisting Opposition', Politics, Philosophy \& Economics, 1, 1 (2002): 109-146. ${ }^{i i}$ Richard Wollheim, 'A Paradox in the Theory of Democracy' in: P. Laslett and W. G. Runciman (eds.) Philosophy, Politics and Society (Oxford: Basil Blackwell, 1962),

iii Sven Ove Hansson, 'A Resolution of Wollheim's Paradox', Dialogue 32, 4 (1993): 681-688. See also his "Preferences and Alternatives," Crítica 31, 92 (1999): 53-66.

${ }^{\text {iv }}$ See, respectively, Jeremy Waldron, Law and Disagreement (Oxford: Oxford University Press, 1999); Goodin op. cit.; Raf Geenens, 'The Deliberative Model of Democracy: Two Critical Remarks', Ratio Juris 20, 3 (2007): 355 371; and Richard Bellamy, 'Democracy, Compromise and the Representation Paradox', Government and Opposition 47, 3 (2012): 441-465.

v Among the former, see Ted Honderich, 'A Difficulty With Democracy', Philosophy \& Public Affairs 3, 2 (1974): 221-226. Among the latter, see Brian Barry, Political Argument (London: Routledge \& Kegan Paul, 1965); Donald D. Weiss, 'Wollheim's Paradox: Survey and Solution', Political Theory 1, 2 (1973): 154-70; and J. Roland Pennock, 'Democracy Is Not Paradoxical: Comment', Political Theory 2, 1 (1974): 88-93.

${ }^{v i}$ See Wollehim op. cit.; Ross Harrison, 'No Paradox in Democracy', Political Studies 18, 4 (1970): 514-17; Vinit Haksar, 'The Alleged Paradox of Democracy', Analysis 37, 1 (1976): 10-1; Waldron op. cit.; and Bellamy op. cit.

${ }^{v i i}$ For a solution to the paradox that considers self-interest, see Ove Hansson op. cit.

viii This, however, need not imply that $\mathrm{X}$ does not any longer have a duty to obey the law. For one thing, reasons other than the ones advanced here may still apply. For another, a content-independent duty to obey the law may exist. For the relationship between democratic legitimacy and political obligation, see Allen Buchanan, "Political Legitimacy and Democracy." Ethics 112, 4 (2002): 689-719; and John A. Simmons, Justification and Legitimacy: Essays on Rights and Obligations (Cambridge: Cambridge University Press, 2001).

${ }^{\text {ix }}$ According to Rawls, "pure procedural justice obtains when there is no independent criterion for the right result: instead there is a correct or fair procedure such that the outcome is likewise correct or fair, whatever it is, provided that the procedure has been properly followed." John Rawls, A Theory of Justice (Cambridge, Mass.: Harvard University Press, 1971), p. 75.

x Goodin op. cit., p. 110.

${ }^{\mathrm{xi}} \mathrm{I}$ am grateful to $\mathrm{X}$ for pressing me to introduce this caveat.

xii For a similar point, see Keith Graham, 'Democracy, Paradox, and the Real World', Proceedings of the Aristotelian Society 76 (1976): 227-245, p. 229.

xiii On this, see Goodin op. cit. p. 135; Wollheim op. cit., p. 80.

${ }^{\text {xiv }}$ Waldron op. cit., p. 101.

${ }^{\mathrm{xv}}$ See Wollheim op. cit., p. 81; Graham op. cit., p. 229

${ }^{x v i}$ Some have accordingly argued that power should be distributed in proportion to people's stakes in the policy under consideration. See Harry Brighouse and Marc Fleurbaey, 'Democracy and Proportionality,' Journal of Political Philosophy 18 (2010): 137-155. Here, however, I put this possibility aside, assuming that stakes are homogenously distributed across the relevant constituency.

xvii I am grateful to $\mathrm{X}$ for raising this objection.

xviii See Jason Brennan, 'Polluting the Polls: When Citizens Should not Vote', Australasian Journal of Philosophy 87 (2009): 535-549, p. 535. More on the right to do wrong below in section 5.

${ }^{x i x}$ I discuss the implications of this in my Iñigo González-Ricoy, 'Depoliticising the polls: Voting abstention and moral disagreement', Politics 32,1 (2012): 46-51. 10.1111/j.1467-9256.2011.01424.x
} 
${ }^{x x}$ For this argument, see Weiss op. cit.

${ }^{x x i}$ For the most forceful account of pure instrumentalism, see Richard Arneson, 'Democracy Is Not Intrinsically Just' in Keith Dowding, Robert E. Goodin and Carole Pateman (eds.), Democracy and Justice (Cambridge: Cambridge University Press, 2004), p. 43.

xxii Barry op. cit., p. 259.

xxiii See Haksar op. cit., p. 12

xxiv The locus classicus is W. Laurens Walker and J. Thibaut, Procedural Justice: A Psychological Analysis (Hilsdale, NJ: L. Erlbaum Associates, 1975). See, more recently, R. J. Dalton, D. C. Shin and W. Jou, 'Understanding Democracy: Data from Unlikely Places', Journal of Democracy 18 (2007): 142-156; C. Carman, 'The Process is the Reality: Perceptions of Procedural Fairness and Participatory Democracy', Political Studies 58 (2010): 731-751; and A. Stutzer and B. S. Frey, 'Political Participation and Procedural Utility: An Empirical Study', European Journal of Political Research 45 (2006): 391-418.

${ }^{\mathrm{xxv}}$ T. R. Tyler, 'Social Justice: Outcome and Procedure', International Journal of Psychology 35 (2000): 117-125, p. 120.

xxvi Jason Brennan, 'Political Liberty: Who Needs It?,” Social Philosophy \& Policy 29, 1 (2012): 1-27, pp. 6-10.

xxvii For a criticism of the separation that targets Arneson's instrumentalism, see Robert Sudgen, 'Justified to Whom?', The Idea of Democracy, David Copp, Jean Hampton and John E. Roemer, eds. (Cambridge: Cambridge University Press, 1993), p. 152.

xxviii Arneson op. cit., p. 43.

${ }^{x x i x}$ See, for example, Arneson op. cit., and Philipe Van Parijs, 'Justice and Democracy: Are They Incompatible?,' Journal of Political Philosophy 4, 2 (1996): 101-117.

${ }^{\mathrm{xxx}}$ For a similar argument, see Brian Barry, 'Wollheim's Paradox: Comment', Political Theory 1, 3 (1973): $317-322$, p. 318 .

${ }^{x x x i}$ That these two principles are depicted as pertaining to two different levels does not imply any moral hierarchy of one of them over the other. This terminology is used exclusively to express that one of the principles is a first-order principle while the other is a second-order one. It does not have moral connotations.

xxxii Harrison op. cit.

xxxiii Harrison, op. cit., p. 516.

${ }^{\text {xxxiv }}$ It may be objected that the principle of keeping promises is procedural, rather than substantive. Even if correct, this objection would miss Harrison's point, which is that Wollheim's paradox is just an instance of the potential contradiction between general moral principles. In order to avoid the problem, the example of keeping promises could be just replaced by any other substantive general principle that may come into contradiction with the principle of saving lives. I am grateful to $\mathrm{X}$ for raising this issue.

${ }_{\mathrm{xxxv}}$ The solution originally sketched by Wollheim correctly captures this difference of levels. However, Wollheim does not elaborate on the alleged different properties of each level. See Weiss op. cit.

${ }^{x x x v i}$ For a careful analysis of the procedural and substantive dimensions of democratic legitimacy, see José Luis Martí, "The Sources of Legitimacy of Political Decisions: Between Procedure and Substance", in L. Wintgens (ed.), The Theory and Practice of Legislation (London: Ashgate, 2005), pp. 259-281.

xxxvii For a criticism of the idea that proceduralism implies a "deaf and blind" acceptance of whatever outcome follows from fair procedures, see Emmanuela Ceva, 'Just Procedures with Controversial Outcomes: On the Grounds for Substantive Disputation within a Procedural Theory of Justice', Res Publica 15, 3 (2009): $219-235$.

xxxviii As illustration, consider the following statement by a demonstrator in Cairo in the aftermath of the coup, which clearly distinguishes between substantive and procedural reasons to support Morsi and oppose the coup. According to him, the demonstrations "had nothing to do with Morsi, the Muslim Brotherhood, or Islam. It has to do with the fact that they have carried out a coup, it has to do with the polls, and with democracy". "Una multitud islamista pide en El Cairo la restauración de Morsi”, El País, July 12, 2013.

xxxix The classic disagreement-based justification of democratic procedures is Waldron op. cit. See also Thomas Christiano, The Rule of the Many (Boulder, Colorado: Westview Press, 1996) and R. Bellamy (2007), Political Constitutionalism (Cambridge: Cambridge University Press).

${ }^{\mathrm{xl}}$ For the distinction between reasonable and unreasonable disagreement, see John Rawls, Political Liberalism, $2^{\text {nd }}$ ed. (New York: Columbia University Press, 1996). In this paper I assume that the distinction can be traced, yet I remain silent about how to define it. Leif Wenar carefully analyzes the concept in his 'Political Liberalism: An Internal Critique', Ethics 106, 1 (1995): 32-62, pp. 34-35.

${ }^{x l i}$ Waldron op. cit., pp. 247-248.

xlii Laura Valentini, 'Justice, Disagreement and Democracy', British Journal of Political Science. 43, 1 (2013): 177- 
199.

xliii This conclusion can be found, for example, in Valentini, op. cit. pp. 187-189. See also Adam Przeworski, 'SelfEnforcing Democracy' in D. Wittman \& B. Weingast (eds.) Oxford Handbook of Political Economy (New York: Oxford University Press, 2006), p. 312

xliv See Thomas Christiano, 'Waldron on Law and Disagreement', Law \& Philosophy 19, 4 (2000): 513-543; Joshua Kassner, 'Is Really Everything Up For Grabs?', Journal of Political Philosophy: 14, 4 (2006): 482-494; Adam Rieger, 'Voting on Voting Systems, or the Limits of Democracy', Analysis 71, 4 (2011): 641-642.

${ }^{x l v}$ For a possible way out, see Jeremy Waldron, 'The Core of the Case Against Judicial Review', Yale Law Journal 115 (2006): 1346-1406, p. pp. 1371-1372.

${ }^{x l v i}$ For the first reason, see Rawls op. cit. pp. 318-319. See also Meena Krishnamurthy, 'Reconceiving Rawls's Arguments for Political Liberty and Its Fair Value', Social Theory \& Practice 38, 2 (2012): 258-278 and and Iñigo González-Ricoy \& Jahel Queralt Lange, 'Political liberties and social Equality', unpublished. For the second reason, see Thomas Christiano, The Constitution of Equality (New York: Oxford University Press, 2008). Both reasons are critically assessed by Brennan op. cit., pp. 6-10 and 12-17.

xlvii Derek Parfit, On What Matters, vol. 1 (Oxford: Oxford University Press, 2011), p. 66.

xlviii See Ori J. Herstein, 'Defending the Right to Do Wrong', Law \& Philosophy 31 (2012): 343-365, pp. 249-351 and $357-361$.

${ }^{x l i x}$ For the distinction between big (i.e. constitutive) and medium decisions, see Edna Ullman-Margalit, 'Big Decisions: Opting, Converting, Drifting', Royal Institute of Philosophy Suplements 58 (2006): 157-172.

${ }^{1}$ Notice that self-constitution does not imply self-realization. As Raz puts it, "[t]he autonomous person is the one who makes his own life, and he may choose the path of self-realization or reject it." Joseph Raz, The Morality of Freedom (Oxford: Oxford University Press, 1986), p. 376.

${ }^{\text {li }}$ For the distinction between soft and hard paternalism, see Joel Feinberg, Harm to Self (Oxford: Oxford University Press, 1986), ch. 4.

lii Jeremy Waldron, 'A Right to Do Wrong', Ethics 92, 1 (1981): 21-39, p. 37.

liii Gerhard Øverland and Christian Barry, 'Do Democratic Societies Have a Right to Do Wrong?', Journal of Social Philosophy 42, 2 (2011): 111-131, pp. 114-116.

liv This belief is widely assumed in the literature. Gerald Dworkin, for example, defines paternalism as follows: "the interference of a state or an individual with another person, against their will." Gerald Dworkin, "Paternalism," in The Stanford Encyclopedia of Philosophy, ed. Edward N. Zalta (Stanford, CA: Stanford University Press, 2010).

${ }^{l v}$ For alternative attempts to challenge this condition, see Seanna V. Shiffrin, "Paternalism, Unconscionability Doctrine, and Accommodation," Philosophy \& Public Affairs 29 (2000): 205-250. Daniel Groll, "Paternalism, Respect, and the Will," Ethics 122 (2012): 692-720.

lvi For an argument along these lines, see David Estlund, Democratic Authority. A Philosophical Framework (Princeton: Princeton University Press, 2008), pp. 76-78. 